\title{
Toward An Understanding of Developmental Coordination Disorder: Terminological and Diagnostic Issues ${ }^{\S}$
}

\author{
Sheila E. Henderson and Leslie Henderson ${ }^{1}$ \\ School of Psychology and Human Development, Institute of Education, University of \\ London; ${ }^{1}$ Neurosciences Division, Faculty of Medicine at Charing Cross Hospital, Imperial \\ College of Science Technology and Medicine, London, United Kingdom
}

\begin{abstract}
Awareness of children who experience unexpected difficulty in the acquisition of motor skills has increased dramatically over the last twenty years. Although the positing of a distinct syndrome has proven seminal in provoking further questions, several basic terminological problems remain unresolved. In this paper, we conduct a component analysis of the three, principal competing labels for this disorder, two of them being elements derived from systematic diagnostic frameworks. Our preference for the DSM IV term Developmental Coordination Disorder (DCD) is stated and justified. Problems in diagnosis are discussed, especially in relation to the etiology-dominated medical model. We argue that an attempt should be made to identify (pathological) positive signs that can reliably be detected rather than relying entirely on normative evidence of a lack of skills exhibited by other children of the same age. The high degree of overlap between DCD and other developmental disorders suggests that DCD might not constitute a distinct syndrome. In this context, we emphasize the
\end{abstract}

need to determine whether incoordination takes a different form when it occurs alone or whether it is combined with general developmental delay or with other specific disorders in children of normal intelligence.

\section{KEYWORDS}

assessment, clumsiness, co-morbidity, diagnosis, dyspraxia, terminology

\section{INTRODUCTION}

It has been recognized for a long time that severe and persistent difficulties in spoken language, reading and writing, attention and motor coordination, not infrequently occur in children of normal general intelligence without any obvious neurological disorder, who come from an unremarkable family background, and who have apparently adequate schooling and other educational experiences (Rutter, 1998, p.ix).

In this paper, our concern is with such unaccountable failures within the domain of motor

\footnotetext{
${ }^{\S}$ This paper is adapted from parts one and two of the Second Lawrence Rarick Commemorative Lecture, presented at the $13^{\text {th }}$ International Symposium for Adapted Physical Activity in Vienna (2001) and published in Adapted Physical Activity Quarterly, 2002, 19, 12-31, (copyright Human Kinetics Publications Inc.) and is reprinted here with permission of the publishers

Reprint requests to: Leslie Henderson, 4 Manor View, Hartford, Huntingdon, Cambs PE29 IWD, United Kingdom. e-mail: I.henderson@ic.ac.uk
} 
skills acquisition and, in particular, what to call this disorder and how to arrive at a systematic diagnosis. Everyday motor skills are not generally as dependent on formal tuition as is, say, mathematical problem-solving or reading aloud. Many actions that we perform in everyday life have been learned informally and can be performed without close attention. Indeed, under normal circumstances, we become aware of the intricate coordination required by our actions only when suddenly deprived of our skill, as in the attempt to fasten buttons with icy fingers. Interestingly, the colloquial term 'clumsy', used of unskilled action, derives from a Middle English word expressing the idea of numbness. Cold fingers as a prototype for incoordination, may have a lexicographic precedent, because, as Partridge (1961) has pointed out, the Middle English clumsed bears a striking morphological resemblance to clumsig, a Swedish dialect word carrying the sense of numb with cold. A reminder of the movement skills we take for granted is also furnished by the child who cannot acquire even the simplest motor skill without help. Being unable to fasten one's buttons or to ride a bike to school might seem trivial disabilities, but it is now well established that such failures can exercise far reaching consequences (see below).

Figure 1 shows examples of deficient graphic skills taken from two children, both aged 9 and with at least a normal IQ. Neither child showed any sign of a central language disorder; both had fluent, accurate speech and read well above their age level. The children came from supportive home backgrounds and attended caring schools. Their parents and teachers were concerned about how
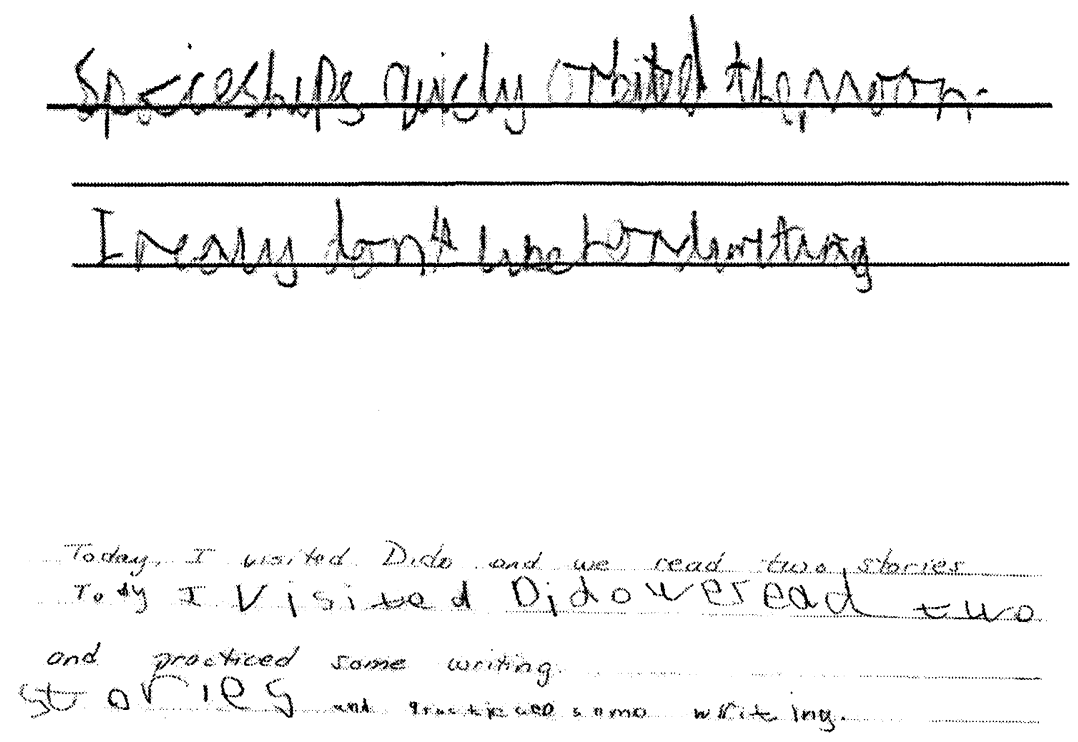

Fig. 1: Examples of defective graphic skills drawn from two children with general movement problems. 
these difficulties might affect the child's progress in school. The advice of pediatricians was sought but they could offer neither a satisfactory explanation of the child's difficulties nor a solution to the problem. Although the deficiencies shown in Fig. 1 should be evident to anyone experienced in children's handwriting, no frozen view of the graphic product can rival in clinical richness the experience of watching the child struggle to generate that product.

Although the awareness of children with difficulties of this sort has greatly increased over the last quarter century, much remains to be learned. In particular, improvements in the assessment of the condition and a greater awareness of its likely accompaniments and possible consequences have not been matched by a commensurate improvement in our understanding of the functional architecture that supports normal competence or the biological and computational bases of deficient skill.

\section{Terminology}

The debate about the appropriate label for a disorder might seem to be of purely 'academic' interest. Nevertheless, the choice of terms has important implications, both theoretical and practical. In research, for example, terminological ambiguities create difficulties in the definition and comparison of samples. In the realm of the practical, a condition defined by society in one way may confer special entitlement to benefits and services, whereas the same condition defined in a different way may not. Labels, moreover, tend to be adhesive, and can therefore be difficult to shed, even when the child has changed for the better. Such issues are addressed in an admirably succinct series of editorials in the journal Developmental Medicine and Child Neurology (for example, Bax, 1999; Davies, 1994; Gardner-Medwin, 1995; Hart, 1999; MacKeith, 1968).

Recent reviews on the labeling of the disorder concerning us here have concluded that terminology continues to present a problem (Henderson \& Barnett, 1998; Polatjako, 1998). To some extent, the variations in labels are systematic, differing characteristically from country to country, from profession to profession, and even according to the theoretical bias of the individual. Surveys by Missiuna \& Polatajko (1995), Miyahara \& Register (2000), and Peters et al., (2001) have shown that certain professionals view the competing labels as interchangeable, whereas others employ different labels for different groups of children. In Sweden, such children are nearly always assigned the label Disorder of Attention and Motor Performance (DAMP), (for example, Gillberg, 1992; Gillberg \& Gillberg, 1989; Gillberg et al., 1989). Transported to Italy, the children become Dyspraxic (Zoia, 1999), whereas in Holland most turn out to have Developmental Coordination Disorder (Geuze et al., 2001). Many Australian practitioners, indifferent to fashion, still use the term Minimal Neurological Dysfunction (Larkin, personal communication). In New Zealand, however, Developmental Dyspraxia is more common (Miyahara \& Register, 2000). In Canada, 6 years after the ironically named 'Consensus Forum' (Polatajko et al.1995), the term physical awkwardness continues to enjoy popularity amongst educators. In the United States, too, different professions employ labels of their own, but for parents seeking private services, insurance companies recognize Developmental Coordination Disorder (American Psychiatric Association, 1994) (APA), opening their coffers only when the DSM IV diagnostic criteria are fully met. The situation in the United Kingdom (UK) is unresolved. Whereas some therapists and teachers are devoted to the term dyspraxic, others use the term $D C D$ (Peters et al., 2001). In contrast, the UK National Health Service (NHS, 1999) has recently been considering the possibility that all hospital records should adhere to the World Health Organization (WHO) classification scheme. Consequently, the 
condition would then bear the catchy WHO title Specific Developmental Disorder of Motor Function (SDD-MF) (ICD 10, 1992).

At the London (Ontario, Canada) Consensus Forum, researchers and practitioners from a wide range of disciplines were able to reach agreement that the term DCD should be universally adopted (Polatajko et al. 1995). In what follows, we reconsider the issues in terms of a component analysis of the three main contending labels: Developmental Coordination Disorder (DCD), Specific Developmental Disorder of Motor Function (SDD-MF) and (Developmental) Dyspraxia. Whereas DCD and SDD-MF have a relatively formal status, due to their APA and WHO provenance, and are linked, as we shall see, to a diagnostic framework (albeit underspecified), Dyspraxia has a more popular appeal, due in part to its 'medical' resonance. The term has never, to our knowledge, been linked to a systematic set of diagnostic criteria. Neither the APA nor the WHO has attempted to justify their choice of term. Instead, both organizations assert, somewhat gnomically, that (a) the classification scheme adopted and the terminology used is not based on theory but on clinical expertise, (b) terms derived from controversial theories have been avoided, and (c) the current state of knowledge of childhood disorders rules out reference to etiology or pathophysiology. If only this agreement on strategy had yielded an agreed label!

The overriding reasons for declining to adopt the term dyspraxia to encompass the sort of unexpected failure to acquire adequate motor skills with which we are here concerned are twofold: the longstanding confusion about the meaning of the term 'apraxia' in the literature on acquired disorders, and the questionable relevance of this literature to the developmental disorder.

It is not difficult to find neurological patients, who, when asked: "show me how you wave goodbye" are unable to do so, but then do so spontaneously, as they depart. The prevailing uncertainty about the nature of this disability was advertised by an unhealthy proliferation of labels, such as ideational, ideomotor, and constructional apraxia, or dressing, gaze, and limb apraxia, and so on. Perhaps in reaction to this, the literature on the apraxias has recently tended to become more empirical, attempting to tie detailed neuropsychological description of the impairment to pathoanatomy (for example, Square et al., 1997). Such locationalist objectives, however worthy, are unlikely to commend the program to those who are primarily concerned with psychological development. Moreover, the attempts to define apraxia continue to generate confusion, ranging from overinclusive to excessively narrow formulations. Over-inclusion may be instanced by Rothi and Heilman's (1997, p. 3) definition: "a neurological disorder of learned purposive movement skill that is not explained by deficits of elemental [sic!] motor or sensory systems." Narrowness is evident in the strangely common assertion that apraxia may be regarded as a disorder of gesture.

Apparently, apraxic difficulties-whatever their nature-do not involve a disturbance in the coordination of movement (but see Poizner et al., 1997). Instead, widely agreed is that the defect is located at a higher level in the hierarchy of action control, in which either the planning of action or the retrieval of action plans has become unduly context-dependent, in that the patient can perform only the act of waving good-bye in 'natural' circumstances. Conversely, in our clinical experience children with a developmental impairment of movement who exhibit the sort of difficulties found in apraxic adults are vanishingly rare. In the great preponderance of cases of such a disorder, incoordination is the most obvious feature presented.

Those who continue to advocate the adoption of the label developmental dyspraxia as an umbrella term in face of these problems risk appearing to be motivated by political rather than 
by scientific considerations or to have been seduced by the medical resonance of the term praxis. The persistent belief that studies of the acquired disorder will somehow nurture the understanding of the developmental condition (for example, Ayres et al., 1987; Denckla, 1984; Dewey, 1995) seems to survive any amount of disappointment. Finally, note that the distinction between developmental and acquired disorders has somehow become entangled with the distinction between the prefix $d y s$ - (signifying disturbance of) and the prefix $a$ - (denoting absence of).

The remaining (APA, WHO) contenders both stem from a tradition in which all developmental disorders were labeled as 'specific'. With the advent of DSM IV (1994), the APA departed from this usage, abandoning the whole notion of specificity. The broader issue was one in which children's learning difficulties were held to be specific only if their achievements fell below what might have been expected on the basis of their general aptitude. The underlying assumption was that specific disorders differed in nature from a more global, developmental delay. Over the last decade, this idea has been severely challenged in many domains, particularly in those of language impairment and dyslexia (see Bishop, 1998, Dowdney \& Scott, 1998; Rispens et al., 1998; Yule, 1998, for penetrating reviews). Sadly, it remains untested in the motor domain.

So, how are we to proceed? Pragmatism suggests that, from a research standpoint, we should continue to employ some sort of discrepancy criterion in the selection of participants, if only to avoid dipping deeply into the murky etiological soup of profound retardation. This approach is not a principled adoption of the specificity notion, however, nor is it an endorsement of IQ as a divine basis for the calculation of discrepancies (see also Geuze, et al., 2001). We are learning from other domains that in clinical practice, the discrepancy concept has little role to play in deciding who should receive inter- vention and what the nature of that intervention should be (see, for example, Stanovitch, 1998, on reading). As Bishop has observed of the language domain, "...there seems little justification for continuing to place heavy reliance on 'IQ-language' discrepancies in determining who should receive extra help at school" (Bishop, 1998, p. 146).

The inclusion of the term developmental in both manuals serves to remind us of the longitudinal perspective, encompassing, in Rutter's eloquent words "...not only the roots of behaviour in prior maturation, in physical influences (both internal and external), and in the residues of earlier experiences, but also the modulations of that behaviour by the circumstances of the present" (Rutter, 1980 p. 1). Although now well established, the notion that most children with movement difficulties will spontaneously out grow them is illfounded (for example, Cantell et al. 1994; Geuze \& Borger, 1993; Henderson, 1993; Losse et al. 1991). Without intervention, the educational, social, and psychiatric consequences can be substantial (for example Hellgren et al., 1994; Hellgren et al., 1994; Hellgren et al., 1993; Skinner \& Piek, 2001). Nevertheless, we cannot predict with any degree of accuracy which child will grow out of the problem or which will become seriously depressed. Only further research will help us to disentangle the complex interactions between organic and environmental factors that might affect the course of DCD.

If one crucial aspect of the term developmental is reference to the interplay of biological with personal and social factors in the child's progressive mastery of its environment, another must surely be the contrast between disorders that are due to the child's failure to learn and those in which a oncelearned skill has been traumatically lost. In the developmental disorder, the most basic of skillssuch as reaching, grasping, standing, and walkingcan be intact but more complicated acts like cutting with scissors or catching a ball represent entirely novel tasks that are often acquired only with the 
utmost difficulty. This situation contrasts markedly with adult conditions in which the same complex skills can be performed with perfection until disaster strikes.

\section{A disorder of...what?}

Whereas DSM IV considers the answer to this question to be motor "coordination", ICD-10 speaks of a disorder of "motor function". The Oxford English Dictionary (OED) defines the term function as activity (or) action in general, whether mental or physical. A possible disadvantage of the term function is that it leaves open the possibility that a child has poor motor function for reasons unrelated to his/her ability to control the motor system. For example, some children with Attention Deficit Hyperactivity Disorder (ADHD) appear clumsy because they are inattentive rather than actually incapable of performing the required actions. Physical weakness, consequent on a musclewasting disease, can also impair motor function without being a primary disorder of motor control.

In contrast to the term 'function', the term 'coordination' seems to refer more directly to the heart of the problem while at the same time remaining fairly neutral as to detailed causality. The Collins English Dictionary defines the verb to coordinate as "to oiganize or integrate diverse elements in a harmonious operation". The OED entry, on the other hand, emphasizes the sequential nature of the movement elements of which most actions are composed: ... "consisting of a number of actions or processes properly combined for one purpose".

Within the scientific literature on motor control, the definitions of coordination vary considerably in their level of discourse. For Schmidt (1988), the term occurs at a level involving individual joints and muscles. Thus, he defines coordination as the "behaviour of two or more joints and muscles in relation to each other to produce skilled activity".
Gallistel (1980), in his monumental treatise The Organization of Action, takes a broader perspective, (see especially Chapter 8). His main preoccupation in this work was identifying the principal functional units that contribute to sustained purposive action. He discusses three types (reflexes, oscillators, and servomechanisms) and considers how they can interact to produce a larger vocabulary of actions. Then, in a key passage, he argues, "These diverse modes of interaction do not, however, by themselves ensure the coherence of coordinated action." This coherence depends upon a hierarchical structuring of the units. By this means, "the highest levels of neural integration impose an overall direction on behaviour." (p. 210).

For Gallistel, coordination is a feature that takes place throughout the hierarchy of action control. Opposing muscles must be activated or inhibited to produce movement of a limb. This parallel selection may be modulated over time, as in oscillator-driven movement, requiring the coordination of temporal patterns. Such patterns can, in turn, be selected or deselected by a higher level decision-making system, in light of environmental data, and so on, up the hierarchy. We can quite properly speak of coordination at each hierarchical level. As we ascend the hierarchy, information from the environment becomes increasingly important so that not only the components of the movement have to be coordinated but also the actions have to fit the coordinates of the environment. The grasping hand has to be shaped to accommodate the arriving ball. At each new level, coordination will exhibit new properties of fluency, appropriateness, and expertise.

In sum, four attractive features emerge from our examination of the term coordination.

- First, the notion of intentionality is embraced.

- Second, our attention is drawn to the spatial and temporal organization of actions.

- Third, we are reminded that most actions involve the sequencing of movement elements. 
- Fourth, we are also reminded that actions have to be appropriately calibrated to environmental coordinates.

Given our implacable hostility to a formal linkage of the developmental disorder to those acquired disorders referred to as apraxias, our approval of the term coordination as a descriptor of the demands of movement control at various hierarchical levels and the eschewal of the problematic notion of specificity, we cannot do other than endorse the label $D C D$.

\section{DIAGNOSIS}

In DSM IV, a disorder is conceptualized as a clinically significant, behavioral or psychological syndrome that is associated with an impairment in one or more important areas of functioning. A syndrome can, in turn, be regarded as a set of co- occurring signs and symptoms indicative of a particular 'disease'. In medicine, diseases are diagnosed in terms of a pattern of abnormal signs and symptoms, sometimes assigned different weights and not all of which may be present in a given case. In well-understood diseases, the etiology is known and defines the disease and specifies any underlying pathophysiology. An effective therapy stems from understanding the etiology, whereas failure of this therapy constitutes a prima facie reason for doubting the diagnosis. Thus, for example, for a condition such as congenital hypothyroidism (a genetic condition resulting in a hormonal deficit), doctors have available to them a proactive screening program leading to early diagnosis and, in consequence, to a rapidly instituted treatment. If treatment is instigated early enough, the catastrophic effects on cognitive and on motor development are averted (see Fig. 2). We mention the admirably clear

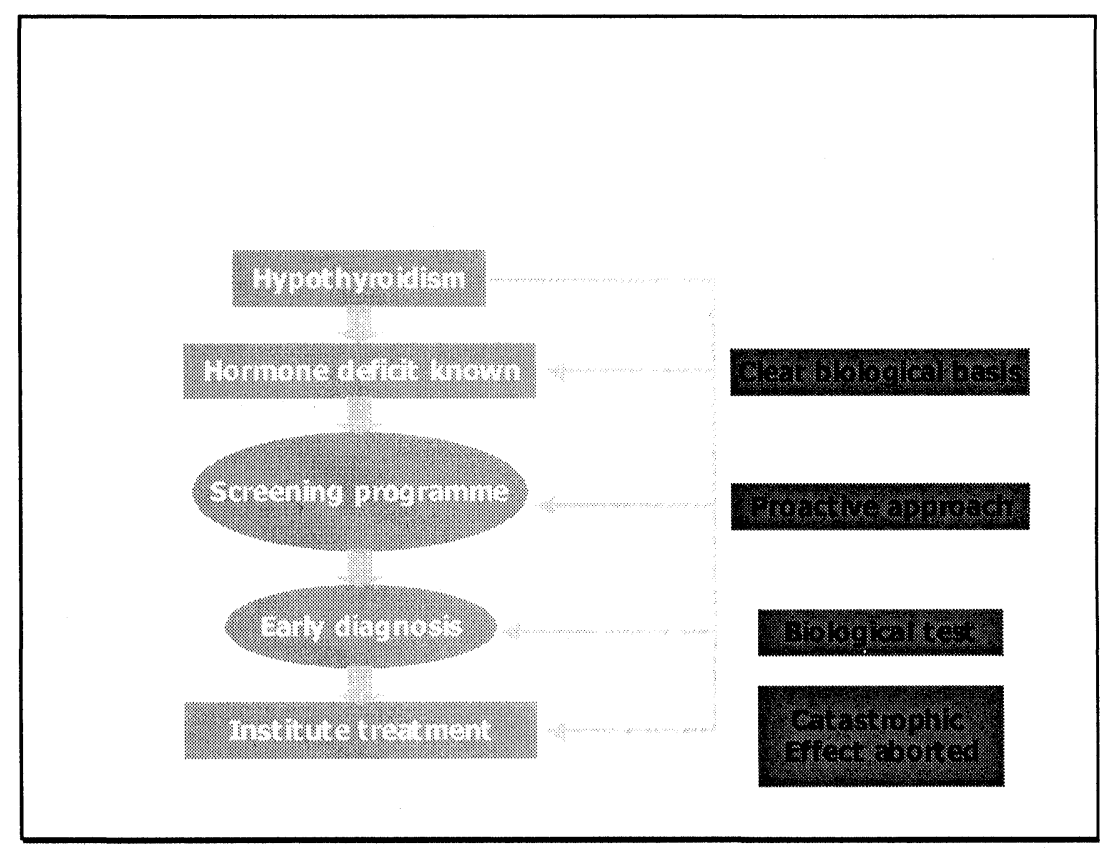

Fig. 2: What makes doctors happy? Congenital hypothyroidism as a prototype of medical diagnosis. (Reprinted with permission of Professor Hilary Cass). 


\section{TABLE 1}

The four DSM IV diagnostic criteria for Developmental Coordination Disorder.

A. Performance in daily activities that require motor coordination is substantially below that expected given the person's chronological age and measured intelligence. This may be manifested by marked delays in achieving motor milestones (for example walking, crawling, sitting), dropping things, 'clumsiness', poor performance in sports, or poor handwriting.

B. The disturbance in Criterion A significantly interferes with academic achievement or activities of daily living.

C. The disturbance is not due to a general medical condition (for example cerebral palsy, hemiplegia, or muscular dystrophy) and does not meet the criteria for a Pervasive Developmental disorder.

D. If mental retardation is present the motor difficulties are in excess of those usually associated with it.

medical disease model precisely because it tells us so little about the diagnosis of DCD. In this, our inspiration might have been that of Artemus Ward's celebrated Lecture, of which the author remarked that its principal virtue was that:

“...it contains so many things that don't have anything to do with it" (Browne, 1865).

Consider the diagnostic guidelines for DCD offered in DSM IV (Table 1). Four criteria are applied. Two are inclusive (the criteria must be satisfied if the diagnosis is to be assigned), and two are exclusive (meeting the criteria entails rejection of the diagnosis).

Criterion ' $A$ ' states that a child's performance in daily activities that require motor coordination must be substantially below that expected given his or her chronological age and IQ. The term substantially is often operationalized as meaning a score on a standardized test of motor performance lying more than two standard deviations below the age norm. According to Geuze et al. (2001) (and who are we to dispute it?) the Movement $A B C$ (Henderson \& Sugden, 1992) is now the test most widely cited in the literature for this purpose. Here, however, we must interject the observation that the extant standardized tests vary greatly in breadth of content. Consequently, one cannot assume that identical scores on different tests are directly comparable (Crawford et al., 2001; Dewey \& Wilson, 2001; Geuze et al., 2001; Tan et al., 2001). In our view, a test like the VMI (Beery, 1982), for example, is too narrowly based to serve diagnosis, unsupported, and this is reflected in a low correlation with broader based tests (for example Jongmans et al., 1998). Criterion ' $\mathrm{B}$ ' is much more difficult to operationalize, requiring the assessor to judge whether the deficit interferes to a significant extent with academic achievements or with the activities of daily living (for example, Watkinson et al., 2001).

Criterion ' $C$ ' states that the deficit must not be due to a medical condition like cerebral palsy and must not satisfy the diagnostic requirements of the generally debilitating group of disorders known as pervasive developmental disorders (which include autism). Finally, Criterion D states that, if mental retardation is present, the motor difficulties must be greater than those to be expected on that basis alone (for extensive reviews of these criteria and their application, see Henderson \& Barnett, 1998; Dewey \& Wilson, 2001; Geuze et al., 2001).

How does this kind of diagnostic protocol deviate from the classic medical model? In acquired disorders of movement like Parkinson's disease, the cardinal symptoms include positive features, 
such as resting tremor and 'cogwheel' rigidity, that are present in patients but not in healthy individuals, as well as negative features like abnormal slowness of movement, where the patient lacks the speed of movement available to the healthy individual). In contrast, the performance features specified in DSM IV(R) for DCD are not pathological and can only be said to be abnormal in a statistical sense.

Positive features are not, however, the preserve of acquired disorders. The obsessional interests and stereotypies of autism and the hyperactivity of children with ADHD seem to have discriminable positive aspects. If positive symptoms could be said to characterize DCD, then they might comprise an awkward or influent style of performance, an aspect of performance we can all observe and agree on but that is difficult to assess with any objectivity. Another very interesting possibility is that in DCD, difficulties with motor control might exert demands on attention resources and working memory that are not present in children whose development is normal. The lack of agreed positive features means, however, that diagnosis has to be based on norm-referenced test items that yield a continuous measure of performance, such as time spent balancing on one leg, for which we can derive statistically determined cut-off points.

If the signs and symptoms of DCD do not comprise a distinct set of pathognomic features, we can still enquire whether they form a cohesive pattern at a functional level. Like schizophrenia, DCD is of unknown etiology and lacks a biological marker. Nevertheless, the symptoms of schizophrenia do seem to form two distinct clusters. A set of positive symptoms (abnormal by their presence), such as hallucinations and delusions, consists of features in which reality testing has broken down in a manner unknown to normal individuals. In contrast, the negative signs (abnormal by their absence) of schizophrenia are characterized by the lack of attributes like motivation or expressions of emotion, present in normal individuals. Crude though it may be, this distinction has been a fertile source of further hypotheses about the action of neuroleptic medication, the chronic effects of institutionalization, and the possibility of subtypes.

Within the literature on DCD, a number of studies have attempted to define subtypes of the disorder (for example, Dewey \& Kaplan, 1994; Hoare, 1994; Jongmans, 1993; Macnab et al., 2001). In our view, however, none of the subtypes proposed have been properly validated and there is, as yet, no really persuasive evidence to suggest that the motor features form cohesive and contrasting clusters. One problem is the lack of general theories in the motor domain that delineate important distinctions between tasks, in terms of their processing requirements. Although, in the construction of most standardized tests, some attempt has been made to include a range of items that straddle an intuitive taxonomy of everyday actions, these different types of test item cannot be said to reflect theoretically-motivated distinctions, of a similar status, say, to that drawn in research on reading, between the processing requirements of printed words whose pronunciation can be assembled by phonographic rules $(\mathrm{d} / \mathrm{o} / \mathrm{g}=$ "dawg") and those requiring lexical retrieval (two = "tooh").

Another problem is the lack of conclusive evidence that the features of DCD, as a whole, comprise a set that is reliably distinguishable from the features of other developmental disorders. The notion of separable syndromes implies that each disorder constitutes a discrete clinical entity. This issue is sometimes expressed in the question of whether coordination difficulties amount to a syndrome or are merely a symptom. In this regard, concern with what sort of creature DCD might be reflects wider doubts about the whole idea of specific developmental disorders as distinct and independent clinical entities. These doubts are nicely captured by two quotations from the recent 
literature that have a remarkable consonance:

- "Those with highly specific deficits are the exception rather than the rule" (Hill et al., 1998, p. 656).

- "Comorbidity is the rule, rather than the exception" (Kaplan et al., 1998, p. 484).

In the limited space available, we shall mention just two studies that address these issues, in rather different ways. The first surveys a substantial portion of the territory of comorbidity, the second concentrates on the nature and extent of motor difficulties in children with DCD and in a quite different disorder, Asperger's syndrome.

In 1998, Kaplan and colleagues in Canada examined over 200 children, who had been referred to their clinic for attention problems or learning difficulties. All were tested 'blind' on measures of cognitive ability, literacy, attention, and motor performance, and strict criteria were adopted for each of three specific learning difficulties. Only children with an IQ over 75 were included. This examination was not an epidemiologic study, and it is not entirely clear to what population it can be generalized. Nevertheless, the results are very thought provoking.

As Fig. 3 shows, 115 children met the admission criteria for at least one of the three developmental disorders. Of these children, only a minority (46\%) were 'pure' cases. Indeed, one in five actually met the criteria for all three diagnostic categories. Of special interest to us here is that the proportion of children exhibiting co-morbidity was particularly high for children with motor problems. Of a total of 81 children exhibiting coordination difficulties, over two thirds $(68 \%)$ were diagnosed with multiple disorders. From the data, Kaplan et al. concluded that it was likely that a variety of leaning disabilities could occur when the early

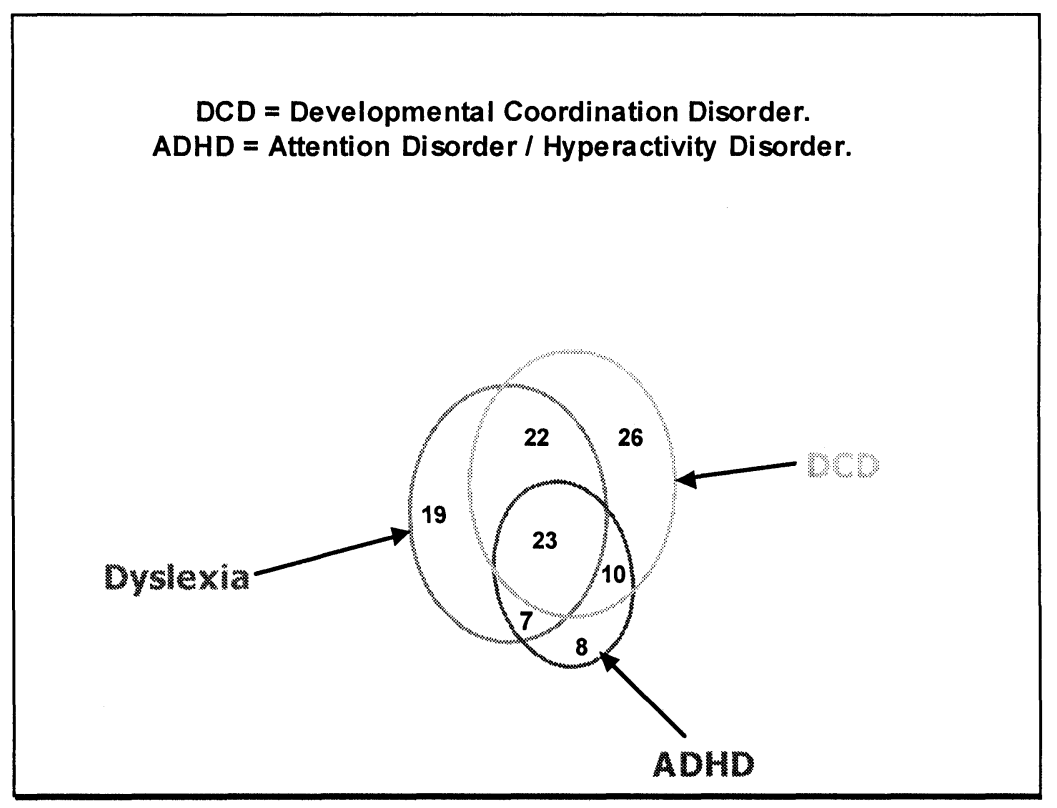

Fig. 3: Venn diagram of co-morbidities, showing number of participants meeting strict criteria for dyslexia, developmental coordination disorder (DCD), and attention deficit / hyperactivity disorder (ADHD), in isolation and in combination, out of a total sample of 224 children referred for learning/attentional difficulties. Data redrawn from Kaplan et al. 1998, with the permission of the publishers. 
development of the brain was disrupted. The specific pattern of the deficits that resulted, however, would depend upon the site and the extent of the damaged neural substrate.

Before we abandon the notion of discrete syndromes entirely, however, it seems worth enquiring whether the motor difficulties experienced by these various groups of children are really identical in nature and extent or whether the difficulties take a discernibly different form when combined with another disorder. Were this the case, then knowledge of the precise nature of these differences might enhance our ability to differentiate between different developmental disorders.

This very question is posed in a more narrowly circumscribed domain by an investigation in which we have recently been involved. Essentially, the work is directed toward a comparison between two developmental disorders that appear to share a component of motor impairment but are very different in other respects (Green, 1997; Green et al., 2002). One group comprises children assigned a diagnosis of Asperger's syndrome by very experienced pediatricians, using ICD-10 criteria. The other group was assigned the diagnosis DCD, also by appropriately qualified and experienced professionals. Although the clinical literature on Asperger's syndrome abounds with descriptions of movement difficulties, we must note that these played no role in the formal diagnosis.

We compared the severity of the movement deficit experienced by these two groups and explored the possibility that the nature of the deficit might differ in the two groups. To this end, we examined the profiles of the children on the Movement $\mathrm{ABC}$, as well as various aspects of their performance on a gesture test. Because Asperger's syndrome is thought to involve defective socialization, we also sought to detect any differential effect of social pressure on motor learning and performance in the two groups. So far, we have found no evidence that clumsiness was more severe or took a systematically different form in DCD when it was not accompanied by the features of Asperger's syndrome than when it was.

\section{ACKNOWLEDGEMENTS}

Anna Barnett, Greg Reid, Dale Ulrich, and Claudine Sherrill provided helpful comments on a draft.

\section{REFERENCES}

American Psychiatric Association. 1994. Diagnostic and Statistical Manual of Mental Disorders, $4^{\text {th }}$ Edition. Washington, DC, USA: APA; 886.

Ayres AJ, Mailloux ZK, Wendler CLW. 1987. Developmental dyspraxia: Is it a unitary function? Occup Ther J Res 7: 93-110.

Bax MCO. 1999. Specific learning disorders/ neurodevelopmental disorders. Dev Med Child Neurol 41: 147. [Editorial]

Bishop D. 1998. Is specific language impairment a valid diagnostic category? Genetic and Psycholinguistic evidence. In: Rispens J, van Yperen TA, Yule W, eds, Perspectives on the Classification of Specific Developmental Disorders. Dordrecht, the Netherlands: Kluwer; 139-155.

Browne CF. (Artemis Ward) 1865. Artemis Ward's Lecture, In: The Oxford Dictionary of Quotations, $2^{\text {nd }}$ Edition. Oxford, UK: Oxford University Press.

Cantell MH, Smyth MM, Ahonen TP. 1994. Clumsiness in adolescence: Educational, motor, and social outcomes of motor delay detected at five years. In: Henderson SE, ed, Developmental Coordination Disorder: A Special Issue, Adapt Phys Act Q 11: 111-236.

Collins English Dictionary $4^{\text {th }}$ Edition. 1992. Glasgow, Scotland: Harper-Collins; 1764.

Crawford S, Wilson BN, \& Dewey D. 2001. Identifying developmental coordination disorder: consistency between tests. Phys Occup Ther Pediatrics 20: 29-50.

Davies PA. 1994. Speaking the same language. Dev Med Child Neurol 36: 189-190. [Editorial] 
Denckla MB. 1984. Developmental dyspraxia: the clumsy child. In: Levene MD, Satz P, eds, Middle Childhood: Developmental Dysfunction. Baltimore, Maryland, USA: University Park Press; 249-272.

Dewey D. 1995. What is developmental Dyspraxia? Brain Cogn 29: 254-274.

Dewey D, Kaplan BJ. 1994. Subtyping of developmental motor deficits. Dev Neuropsychol 10: $265-284$.

Dewey D, Wilson BN. 2001. Developmental coordination disorder: What is it? Phys Occup Ther Pediatr 20: 5-27.

Dowdney L, Scott S, eds. 1998. Forum on Dyslexia. Child Psychol Psychiatry Rev 3: 2-25.

Gallistel CR. 1980. The Organisation of Action: A New Synthesis. Hillsdale, New Jersey, USA: Lawrence Erlbaum; 432.

Gardner-Medwin D. 1995. New medical classifications and languages. Dev Med Child Neurol 37: 283-284. [Editorial]

Geuze RH, Borger H. 1993. Children who are clumsy: five years later. Adapt Phys Act Q 10: 10-21.

Geuze RH, Jongmans MJ, Schoemaker MM, SmitsEngleman BCM. 2001. Clinical and research diagnostic criteria for developmental coordination disorder: a review and discussion. Hum Mov Sci 20: 7-47.

Gillberg C. 1992. Deficits in attention, motor control and perception and other syndromes attributed to minimal brain dysfunction. In: Aicardi J, ed, Diseases of the Nervous System in Childhood, Oxford, UK: Blackwell; 1321-1337.

Gillberg IC, Gillberg C. 1989. Children with preschool minor neurodevelopmental disorders IV: behaviour and school achievement at age 13. Dev Med Child Neurol 31:3-13.

Gillberg IC, Gillberg C, Groth J. 1989. Children with preschool minor neurodevelopmental disorders $\mathrm{V}$ : neurodevelopmental profiles at age 13. Dev Med Child Neurol 31: 14-24.

Green D. 1997. Clumsiness in Asperger's syndrome. Master's Thesis. University of Surrey, UK. [Unpublished]

Green D, Baird G, Barnett AL, Henderson L, Huber J, Henderson SE. 2002. The severity and nature of motor impairment in Asperger's syndrome: A comparison with specific developmental disorder of motor function. J Child Psychol Psychiatry 43: 655-668.

Hart H. 1999. Terminology to benefit children. Dev
Med Child Neurol 41: 651. [Editorial]

Hellgren L, Gillberg IC, Bagenholm A, Gillberg C. 1994a. Children with deficits in attention, motor control and perception (DAMP) almost grown up: psychiatric and personality disorders at age 16 years. J Child Psychol Psychiatry 35: 1255-1271.

Hellgren L, Gillberg C, Gillberg IC. 1994b. Children with deficits in attention, motor control and perception (DAMP) almost grown up: the contribution of various background factors to outcome at the age of 16 years. Eur Child Adolescent Psychiatry 3: 1-15.

Hellgren L, Gillberg C, Gillberg IC, Enerskog I. 1993. Children with deficits in attention, motor control and perception (DAMP) almost grown up: general health at age 16 years. Dev Med Child Neurol 35: 881-892.

Henderson SE, Barnett A. 1998. The classification of specific motor coordination disorders: some problems to be solved. Hum Movement Sci 17: 449-470.

Henderson SE, Sugden DA. 1992. The Movement Assessment Battery for Children. London, UK: The Psychological Corporation; 240.

Henderson SE. 1993. Motor development and minor handicap. In: Kalverboer A, Geuze R, eds, Motor Development in Early and Later Childhood: Longitudinal Approaches. Cambridge, UK: Cambridge University Press; 286-307.

Hill EL, Bishop DVM, Nimmo-Smith I. 1998. Representational gestures in Developmental Coordination Disorder and specific language impairment: Error types and the reliability of ratings. Hum Mov Sci 17: 655-679.

Hoare D. 1994. Subtypes of developmental coordination disorder. Adapt Phys Act Q 11: 158-169.

Jongmans MJ. 1993. Perceptuo-motor competence in prematurely born children at school age: neurological and psychological aspects. Doctoral Thesis, University of London, UK; 327.

Kaplan BJ, Wilson BN, Dewey D, Crawford SG 1998. DCD may not be a discrete disorder. Hur Movement Sci 17: 471-490.

Losse A, Henderson SE, Elliman D, Hall D, Knight E Jongmans M. 1991. Clumsiness in children--dc they grow out of it? A ten year follow-up study Dev Med Child Neurol 33: 55-68.

MacKeith R. 1968. Maximum clarity on neurodevel opmental disorders. Dev Med Child Neurol 10 143-144. [Editorial] 
Macnab JJ, Miller LT, Polatajko HJ. 2001. The search for sub-types of DCD: Is cluster analysis the answer? Hum Mov Sci 20: 49-72.

Missiuna C, Polatajko, H. 1995. Developmental dyspraxia by any other name: Aren't they all just clumsy children? Am J Occup Ther 49: 619-627.

Miyahara M, Register C. 2000. Perceptions of three terms to describe physical awkwardness in children. Res Dev Disabil 21: 367-376.

National Health Service Executive. 1999. Clinical governance: Quality in the new NHS. Bristol, England: NHSE.

The Oxford English Dictionary, Compact Edition. 1979. Oxford, UK: Clarendon Press; 4116.

Partridge E. 1961. Origins: A Short Etymological Dictionary, $5^{\text {th }}$ Edition. London, UK: Routledge \& Kegan Paul; 972.

Peters J, Barnett A, Henderson SE. 2001. Clumsiness, dyspraxia and developmental coordination disorder: how do health and educational professsionals in the UK define the terms? Child Care Health Dev 27: 399-413.

Poizner H, Merians AS, Clark M, Rothi LJ, Heilman KM. 1997. Kinematic approaches to the study of apraxic disorders. In: Rothi LJ, Heilman KM, eds, Apraxia: The Neuropsychology of Action. Hove, East Sussex, UK: Psychology Press; 93-111.

Polatajko HJ. 1998. Developmental Coordination Disorder (DCD) alias the clumsy child. In: Whitmore K, Hart H, Willems GW, eds, A Neurodevelopmental Approach to Specific Learning Disorders: The Clinical Nature of the Problem. London, UK: MacKeith Press; 119-133.

Polatajko H, Fox M, Missiuna C. 1995. An international consensus on children with developmental coordination disorder. Can J Occup Ther 62: 3-6.

Rispens J, van Yperen TA, Yule W, eds, 1998. Perspectives on the Classification of Specific Developmental Disorders. Dordrecht, the Netherlands: Kluwer; 286.

Rothi LJG, Heilman KM. 1997. Apraxia: The Neuropsychology of Action. Hove, East Sussex, UK:
Psychology Press; 312.

Rutter, M, ed, 1980. Scientific Foundations of Developmental Psychiatry. London, UK: Heineman Medical books Ltd; 386.

Rutter M. 1998. Foreword. In: Rispens J, van Yperen TA, Yule W, eds, Perspectives on the classification of specific developmental disorders. Dordrecht, The Netherlands: Kluwer; ix-xviii.

Schmidt RA. 1988. Motor control and learning, $2^{\text {nd }}$ Edition. Champaign, Illinois, USA: Human Kinetics; 578.

Skinner RA, Piek P. 2001. Psychosocial implications of poor motor coordination in children and adolescents. Hum Mov Sci 20: 73-94.

Square PA, Roy EA, Martin RE. 1997. Apraxia of speech: Another form of praxis disruption. In: Rothi LJG, Heilman KM, eds, Apraxia: The Neuropsychology of Action. Hove, East Sussex, UK: Psychology Press; 173-207.

Stanovitch KE. 1998. Refining the phonological core deficit model. In: Dowdney L, Scott S, eds, Forum on Dyslexia. Child Psychol Psychiatr Rev 3: 125.

Tan SK, Parker HE, Larkin D. 2001. Concurrent validity of motor tests used to identify children with motor impairment. Adapt Phys Act Q 18: $168-182$

Ulrich D. 2000. Test of Gross Motor Development, $2^{\text {nd }}$ Edition. San Antonio, Texas, USA: Psychological Corporation; 60.

Watkinson EJ, Causgrove-Dunn J, Cavaliere N, Calzonetti K, Wilhelm L, Dwyer S. 2001. Engagement in playground actitivies as a criterion for diagnosing developmental coordination disorder. Adapt Phys Act Q 18: 18-35.

World Health Organisation. 1992. The ICD-10 Classification of Mental and Behavioural Disorders. Geneva, Switzerland: World Health Organisation; 362.

Zoia S. 1999. Normal and Impaired Motor Skills Development. PhD thesis, University of Trieste; 200 

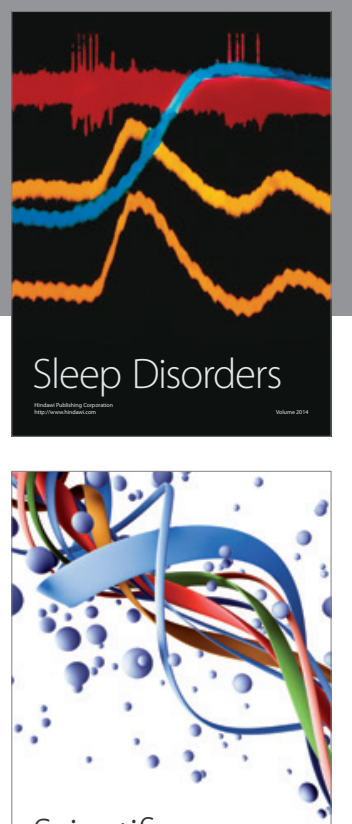

Scientifica
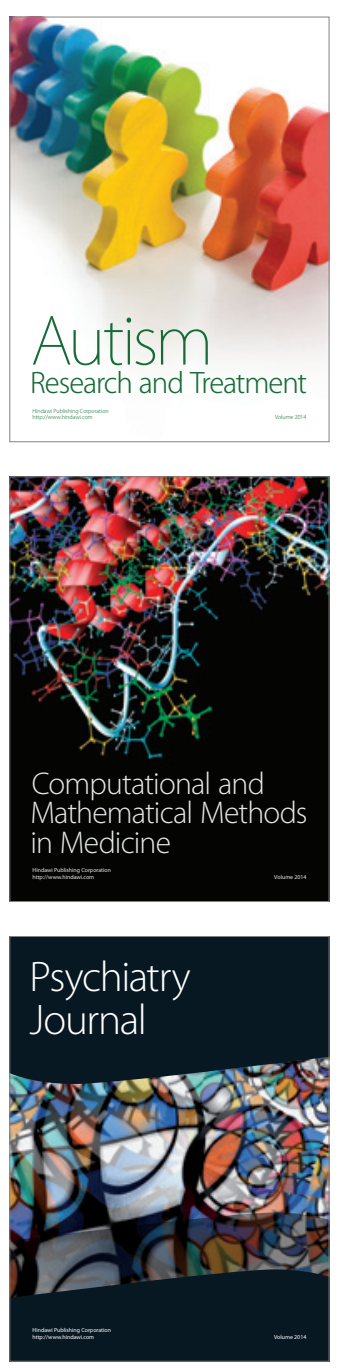
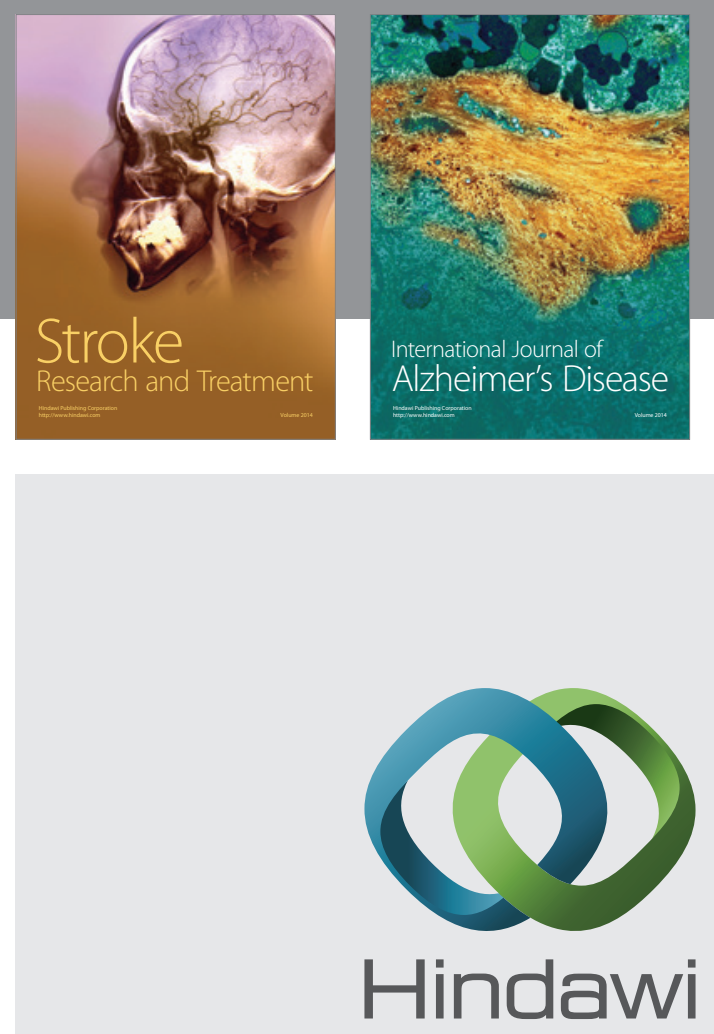

Submit your manuscripts at

http://www.hindawi.com
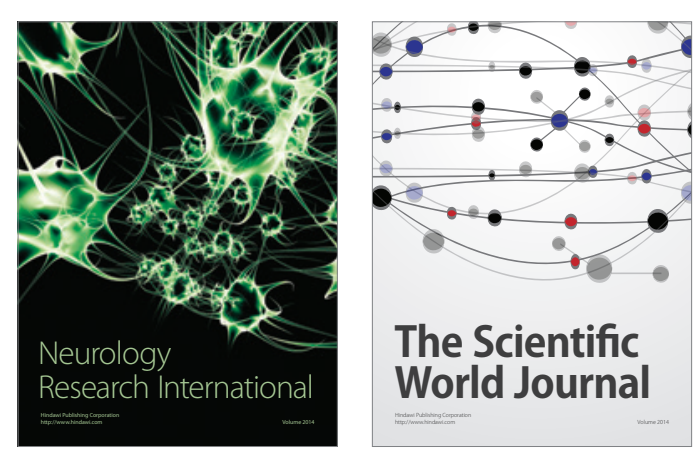

The Scientific World Journal

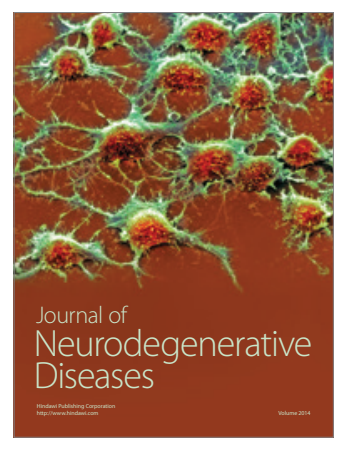

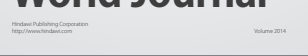

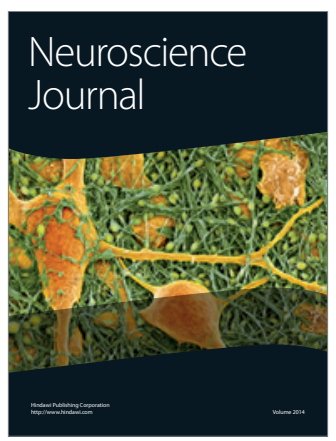

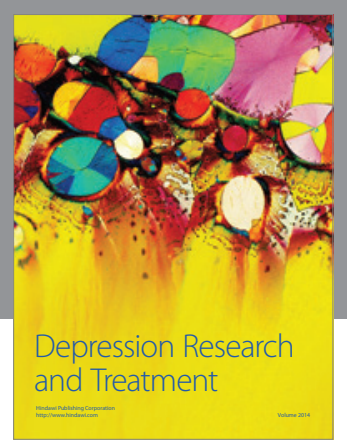
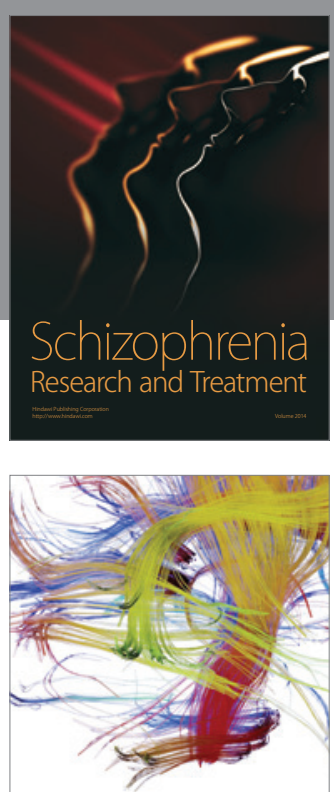

Brain Science

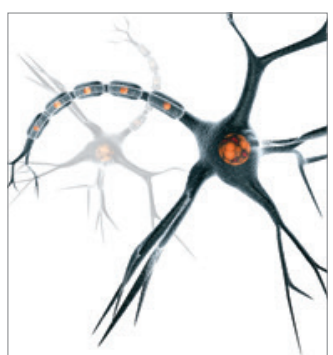

Neural Plasticity
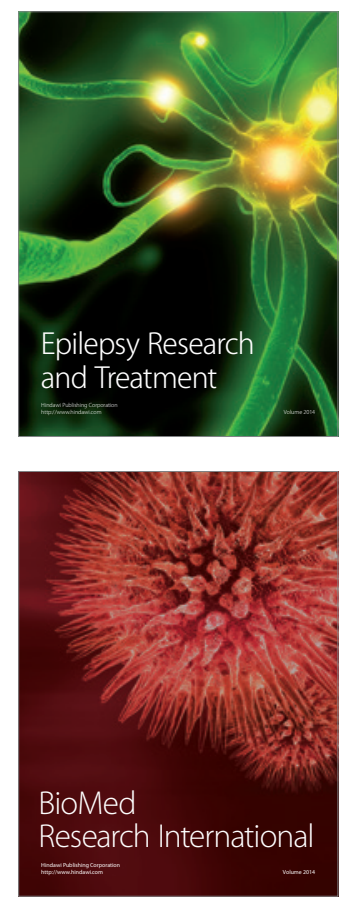

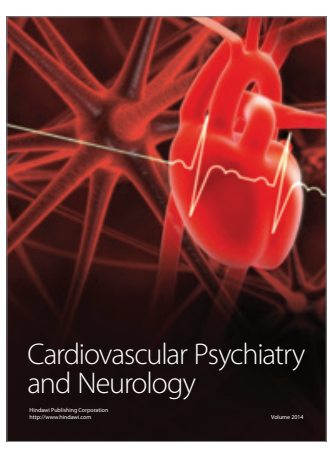

Parkinson's

Disease
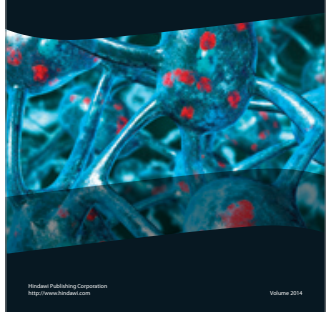